\title{
Gene-Enhanced Personalized Regenerative Medicine for Bone
}

\author{
Firoozeh Alavian ${ }^{1}$, Akram Alizadeh ${ }^{2}$, Sorayya Ghasemi ${ }^{3^{*}}$ \\ ${ }^{1}$ Department of Biology, School of Basic Sciences, Farhangian University, Tehran, Iran \\ ${ }^{2}$ Department of Tissue Engineering and Applied Cell Sciences, Faculty of Medicine, Semnan University of Medical Sciences, Semnan, \\ Iran \\ ${ }^{3}$ Cellular and Molecular Research Center, Basic Health Sciences Institute, Shahrekord University of Medical Sciences, Shahrekord, \\ Iran
}

Corresponding Author: Sorayya Ghasemi, PhD of Medical Genetics, Assistant Professor, Cellular and Molecular Research Center, Basic Health Sciences Institute, Shahrekord University of Medical Sciences, Shahrekord, Iran. Tel: +98-38-33331471, Fax: +98-3833330709, Email: sorayya.ghasemi@gmail.com

Received July 30, 2018; Accepted October 19, 2018; Online Published March 15, 2019

\begin{abstract}
Regenerative medicine (RM) is a developing multidisciplinary science that uses different principles and methods of other fields or sciences for tissue regeneration, repair or replacement. Gene therapy refers to transferring genes or gene expression regulator factors for the desired purposes. In some cases, gene therapy plays an important role in regenerative medicine by modulating stem cells from different sources. Genetic heterogeneity of individuals can affect the results of gene therapy or other therapies in RM. This is why personal genomics should be considered in RM and is called personalized regenerative medicine (PRM). The purpose of PRM is to employ strategies and methods tailored to the individual's genetics in order to efficiently reconstruct or substitute various parts of the body. In this study, the strategies and recent advances in bone regeneration such as gene therapy, epigenetic-based therapies, RNA-based therapy and CRISPR/Cas9 system with an attitude to personalized medicine are introduced. Keywords: Bone, Regenerative Medicine, Gene Therapy, Epigenetic, Personalized Medicine

Citation: Alavian F, Ghasemi S, Alizadeh A. Gene-enhanced personalized regenerative medicine for bone. J Appl Biotechnol Rep. 2019;6(1):1-5. doi:10.29252/JABR.06.01.01.
\end{abstract}

\section{Introduction}

It is said that RM replaces or regenerates human cells, tissue or organs using different cell types and strategies. ${ }^{1}$ Stem cells, as an important source of cells used in regenerative medicine (RM), have the ability to renew themselves for long periods and can be differentiated into various cell types. ${ }^{2,3}$

Gene therapy can modify embryonic/adult stem cells or induced somatic cells into pluripotent stem cells (iPSCs) to further use in RM. Personalized medicine is a novel field of medicine which refers to the employing of specific therapeutics procedure for an individual. This approach has been established based on genomic information and data. Nowadays personalized medicine covers many fields of healthcare such as RM.,

Accordingly, RM and cell-based therapy uses individual cell-based products in order to develop personalized treatments and regeneration. Science the use of gene therapy and personalized medicine can affect the efficiency of the regeneration strategies, it is suggested to apply genomic data of an individual in RM as personalized regenerative medicine or PRM.

In this article, different strategies such as cell therapy, gene therapy, RNA based therapy etc used in bone regeneration according to the use in bone PRM is presented.

\section{Personalized Bone Regeneration}

Personalized RM has 2 concerns. One concern which is related to construct or defect characteristics, is to produce or regenerate tissues or organs with appropriate sizes or dimensions, mechanical properties and etc tailored to the patient. ${ }^{6}$ Another concern which is related to applied strategy is the use of appropriate regeneration techniques tailored to the patient's genetics in order to achieve best results.

In order to appropriately design a construct, the scaffolds should consider the personalized functional requirements such as the external shape and size of the defect, porosity, and stiffness in order to avoid stress shielding and to stimulate the growth of the new tissue. For this purpose, three-dimensional bioprinters and different methods of providing threedimensional scaffolds adapted to the patient's lesion were used. In order to investigate and select patient-centered strategies for bone regeneration, it is necessary for the patient to be genetically examined and gene expression profile, especially in the natural bone tissue must be assayed. For example in

Copyright (C) 2019 The Author(s). This is an open-access article distributed under the terms of the Creative Commons Attribution License (http:// creativecommons.org/licenses/by/4.0), which permits unrestricted use, distribution, and reproduction in any medium, provided the original work is properly cited. 
one patient, the use of gene therapy for a special growth factor may be more effective than other growth factors due to its genetics. In one patient, using siRNA against corticosteroids receptors may be more effective than other strategies. ${ }^{6}$

\section{Personalized Cell Therapy in Bone Regeneration}

There are some limitations in the clinical utility of stem cells. For example the immune rejection of heterologous stem cells, limit their applications. ${ }^{7}$ Also, the low quantity of reachable autologous cells requires in vitro expansion in xeno-derived media and may result in genomic alterations and unwanted cell differentiation and functions. This is why some appropriate tests should be performed for analyzing cells before transplantation. Additionally, the safety and regulation of these procedures must be performed before clinical trials. ${ }^{8-10}$ Banking and the use of human cord blood stem cells or iPSCs) in order to achieve personalized cell source will be an approach in personalized cell therapy in bone regeneration. ${ }^{11}$

\section{Gene Therapy in Bone Regeneration}

Bone regeneration can be enhanced through the delivery of genes or other regulators of genes that stimulate osteogenesis and angiogenesis. ${ }^{12}$ Gene therapy is transferring DNA or RNA into cells for some proposes. ${ }^{13}$ In vivo, ex vivo and in situ approaches are the most popular local gene therapy in RM. The in vivo approach is simple, fast, and less expensive but the ex vivo gene therapy is safer and more helpful; because genetic manipulations get done outside the body. In this method, the progenitor cells can be used as a primer place for bone development. Both methods are presently used for bone regeneration. ${ }^{14}$ Viral and non-viral vectors can be used in RM. ${ }^{14,15}$ Viral and non-viral deliveries have some advantages and disadvantages. Ultimately, clinical trial for gene therapy in bone regeneration is essential for the follow-up study of side effects. ${ }^{13}$
Genes and Factors in Bone Gene Therapy

In general, genes or factors that are used in bone regeneration can be divided into the following. The delivery of growth factor genes and the expression of these genes is the original item for modifying the bone matrix during bone curing for regeneration purposes. ${ }^{16}$ The GF regulate vascularization and induce proliferation and differentiation of osteoprogenitors cells and neighboring tissues in the periodontal and gingival structures. Hence, they can be valuable for improving the repairing processes and to stimulate bone regeneration. Transforming growth factor-b1 (TGFb1) is a growth factor that has an essential role in MSC stimulate to osteoblast precursors and chondrocyte proliferation. Also, TGFb1 has some functions in some extracellular bone matrix protein such as collagen, osteopontin, and alkaline phosphatase. On the other hand, biomaterials were advancely industrialized to combine GFs for synergistic effects on bone regeneration ${ }^{16}$. Finally, vascular endothelial growth factor (VEGF) is an important GF in bone formation and angiogenesis. ${ }^{17,18}$. The GF transcription factors, such as Runx2, Sox9, and Osterix are also necessary for osteoblastogenesis and regulators for osteogenesis of chondrocytes and osteoblasts and have been used in gene therapy for bone regeneration (Figure 1). ${ }^{19}$

\section{Epigenetic Therapy in Bone Regeneration}

Epigenetic modifications lead to functional relevant alterations in the genome without any changes in the nucleotide sequence. ${ }^{21}$ Epigenetic mechanisms play essential roles in stem cell maintenance, differentiation and expression pattern during bone regeneration processes. ${ }^{22}$ In osteogenic differentiation of stem cells, DNA methylation, histone modifications, and microRNAs (miRs) regulation are involved in bone regeneration. ${ }^{23}$ For example, CpG methylation of the osteocalcin promoter considerably decreases during in vitro osteoblast differentiation of MSCs. In addition, hypermethylation of the LIN28 promoter reduces LIN28 expression during osteoblast differentiation. It has

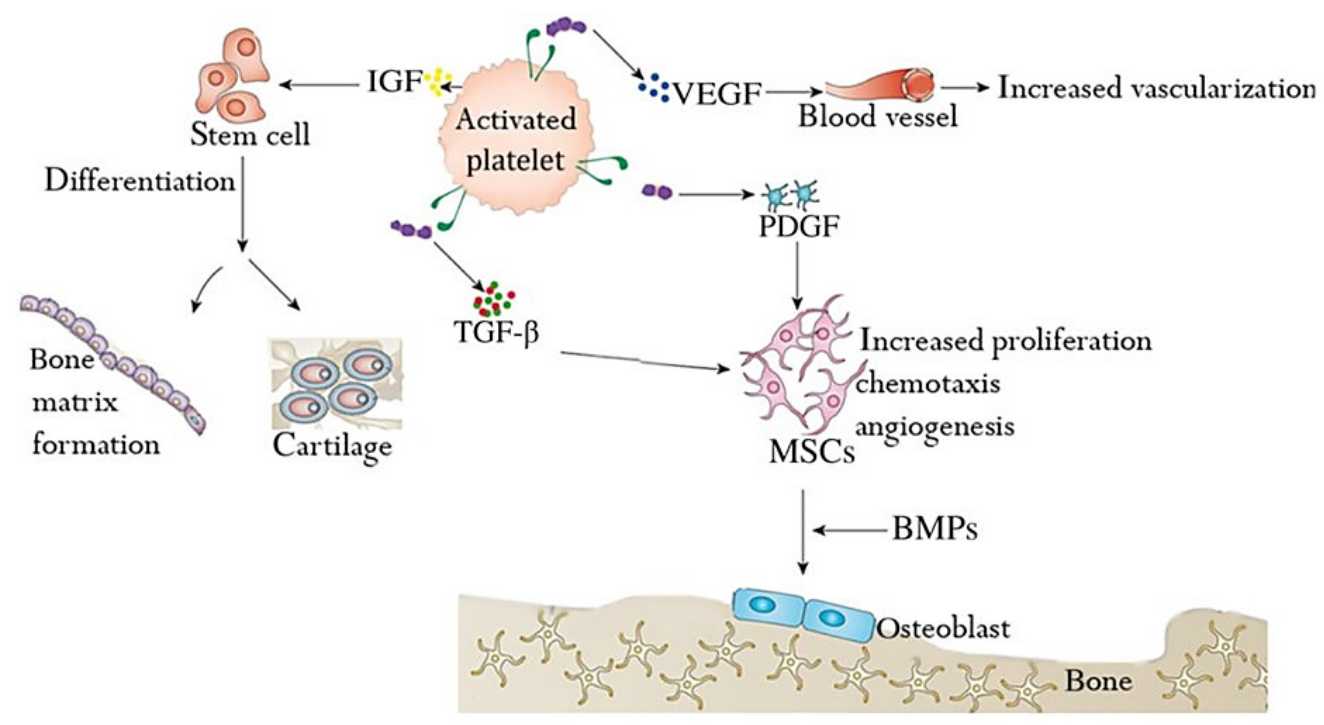

Figure 1. Some of the Factors and Genes Are Shown in Osteogenesis. ${ }^{20}$ 
been demonstrated that the activation of CDK1 promotes osteogenic differentiation of MSCs through phosphorylation of EZH2, the catalytic subunit of PRC2, that in turn catalyzes the methylation of histone $\mathrm{H} 3$ on lysine 27 (H3K27). ${ }^{24}$ However, epigenetic mechanisms are not limited to the following.

\section{MiRs in Bone Regeneration}

The MiRs acts as the main regulators of bone formation, regeneration, and degeneration. ${ }^{25}$ The delivery of miRs is the most common epigenetics control that was used in bone regeneration. They regulate expression of many genes in various vital processes; including growth and differentiation. Also, MiRs play an essential role in any step of bone formation. MiRs regulate expression of genes by targeting mRNAs. ${ }^{26}$ up-regulate or down-regulate occur in miRs expression throughout the development and differentiation process for therapeutic special effects. ${ }^{27}$ Ex vivo manipulation of the miRs levels is an important approach in the differentiation of various stem cells in RM. ${ }^{28}$ The use of miR levels could be an attractive approach for bone regeneration. ${ }^{29}$ MiRs that induced osteogenic had several fundamental functions in the stimulation of bone formation at different stages such as growth and development. Also, miRs contribute to the endochondral ossification process. ${ }^{30}$ So, particular miRs have essential roles in numerous pathways for promoting osteoblast differentiation. ${ }^{31}$ MiRs regulate osteogenic, adipogenic, and chondrogenic differentiation. There have been a number of the significant role of miRs in osteoblast proliferation and differentiation. For example, in positive osteogenesis, miRs can target Runx2 co-repressors in MSCs. This is while during negative osteogenesis, Runx2 or its co-activators can be targeted by miRs. ${ }^{32}$ For example, miR-29 is one type of miRs which its role in bone formation has been determined. Actually, miR-29 can stimulate osteogenic differentiation by targeting negative regulators on the related signaling pathway. It has also been shown that miR-34c with other signaling pathway are involved in osteogenic differentiation in mice. ${ }^{16}$ Studies have shown that miRNA-26a can promote bone regeneration through the positive regulation osteogenesis. ${ }^{33}$

\section{RNA-Based Therapy}

Coding RNAs (mRNAs) code proteins in translation inside ribosome. Non-coding RNA are rRNA, tRNA, snRNA and other regulatory RNAs like short interference RNA (siRNA), microRNA (miRNA), short hairpin RNA (shRNA), Piwi-interacting RNA (piRNA) and Long noncoding RNA (lncRNA). Regulatory RNAs play a critical role in gene expression control in post-transcriptional, genomic and epigenomic levels. ${ }^{34-36}$ the RNA-based therapeutics such as the use of siRNAs, miRNAs, antisense oligonucleotides, aptamers, synthetic mRNAs and clustered regularly interspaced short palindromic repeats (CRISPR). CRISPR-associated protein-9 (Cas9) nuclease are a relatively new class of treatment and prophylactic for a number of chronic and rare diseases. ${ }^{36-39}$ It is also considered as a new method for tissue repair and regeneration (Advances in the delivery of RNA therapeutics: from concept to clinical reality, overcoming cellular barriers for RNA therapeutics, and RNA therapeutics for tissue engineering). RNA therapy because of its cytoplasmic function and degradation reduce the risk and have some advantages. ${ }^{40,41}$ In the context of tissue engineering and RM, the probable turnover of the exogenous RNA is a further advantage. ${ }^{42}$ As conventional RNAs have strong immunogenicity and low stability, chemical modifications are needed to facilitate..$^{25,43}$

\section{CRISPR/Cas9 System}

The CRISPR/CRISPR-Cas9 pathway is revolutionizing biological research. ${ }^{44,45}$ Modifications to this primitive prokaryotic immune system now enable scientists to efficiently edit DNA or modulate gene expression in living eukaryotic cells and organisms. ${ }^{46,47}$ Thus, many laboratories can now perform important experiments that were previously considered as scientifically risky or too costly.

\section{Delivery Approachs for Gene Enhanced Regeneration}

Sustainable local delivery, regulated gene expression, safety and failed clinical trial, are subjects which should be considered in gene therapy for RM. ${ }^{48,49}$ Viral transduction of target cells is a possible approach for regenerative applications. As mentioned, gene therapy by delivery through viral and non-viral vectors, lipid-based delivery systems and polymerbased delivery systems are general approaches for RM. ${ }^{50}$ For gene and often for miRs delivery, systemic or local delivery systems could be used. ${ }^{51}$ Transfection for primary stem cells is more difficult than non-stem cell lines. ${ }^{52}$ Thus more efficient systems for miRs delivery are required for RM. Some regeneration methods are a prolonged process. Depending on the expression levels of the targets, miRs replacement or inhibition therapy that up-regulates miRs expression and down-regulates targets of miRs expression can be done. ${ }^{53}$ Several viral and non-viral vectors with high transfection efficiency, excellent biocompatibility, and high-level targeting efficiencies have been developed. ${ }^{51}$

\section{Viral Delivery Systems}

Gene transfer mediated by viral vectors represents the most common approach in gene therapy studies. ${ }^{54}$ The different types of viral vectors whether integrated or nonintegrated form scan used for RM. ${ }^{55}$ The integrated viruses are important because they are stable and their expressions are continual. Under different conditions, such as bone regeneration, transient transgene expression is useful. For this aim, recombinant adenoviral vectors can be the most attractive. Also adenoviral vectors have the highest level of transgene efficiency. So, the use of adenovirus vectors in bone regeneration is common. Retroviral vectors have been also used in a small amount. ${ }^{14}$

\section{Non-viral Delivery Systems}

Delivery of naked DNA/plasmids contains direct injection, liposome, particle or polymer mediated transfection, electroporation, etc. On the other hand, the use of non-viral delivery systems is limited by their efficiency of transfer and the level of transgene expression. Lipid or polymerbased delivery systems can be used in the various opinion 
of stem cell differentiation. Non-viral transmission systems are not appropriate for clinical applications in some cases. For some purposes such as a systemic anti-miR delivery was recommended nanoparticles and liposomes for delivery. ${ }^{56,57}$

\section{Scaffold-Based Delivery Systems}

The scaffold-based delivery systems were planned to be a successful, stable, low cytotoxicity and efficient non-viral delivery system.${ }^{58}$ Scaffold-mediated delivery via encapsulating the genes or miRs in or onto the tissue engineering scaffold can be used for more controlled and localized transfection in RM applications. The findings show some of the mechanisms of miRs regulation by biomaterials and their development. These delivery systems would have probable curative values in bone regeneration..$^{59}$ Localized and efficient gene transfer can be promoted by exploiting the interaction between the vector or miRs and biomaterial. ${ }^{60}$ Different materials can be designed in order to use as gene delivery systems for bones. Biodegradable natural or synthetic materials or polymers with the potential of attachment and carrying vectors or other nucleic acids and analogs can be used. These systems in addition to carrying and delivering the desired construct can be effective in bone regeneration by itself. ${ }^{61}$ For example, chitosan-based hydrogel have been used in bone regeneration as gene delivery systems to transfer the BMP2 gene. ${ }^{62}$

\section{Conclusions}

Personalized medicine is an important feature in RM. Since bone formation and regeneration processes take place using the cells and the co-expression of many molecules, including GFs, specific transcription factors, and morphogenic bone proteins, the understanding of which of the genes, factors or epigenetic modifications can lead to more success in a patient requires a related genomic analysis of the patient. Application of personalized bone regeneration approaches can greatly alter the outcomes in the near future.

\section{Authors' Contributions}

FA has searched and contributed to writing. AA designed and edited the manuscript. SG has designed and created the article. All authors read and approved the final manuscript.

\section{Conflict of Interest Disclosures}

The authors declare they have no conflicts of interest.

\section{Acknowledgments}

The authors would like to thank the colleagues of the Shahrekord University of Medical Sciences and the Farhangian University for their helpful cooperation.

\section{References}

1. Cossu G, Birchall M, Brown T, et al. Lancet commission: stem cells and regenerative medicine. Lancet. 2018;391(10123):883-910. doi:10.1016/s0140-6736(17)31366-1.

2. Docshin PM, Karpov AA, Eyvazova SD, et al. Activation of Cardiac Stem Cells in Myocardial Infarction. Cell tissue biol. 2018;12(3):175-182. doi:10.1134/s1990519x18030045.

3. Revittser AV, Neguliaev YA. Adipogenic Differentiation of Human Mesenchymal Stem Cells Derived from Fetal Bone Marrow Using Rosiglitazone. Cell tissue biol. 2018;12(5):367-372. doi:10.1134/ s1990519x18050061.
4. Arjmand B, Goodarzi P, Mohamadi-Jahani F, Falahzadeh K, Larijani B. Personalized regenerative medicine. Acta Med Iran. 2017;55(3):144-149.

5. Alavian F. Drug Abuse Treatment through Gene Manipulation Using Nanomedicine. Curr Pharmacogenomics Person Med. 2018;16(3):182-191. doi:10.2174/18756921176661812071207 51.

6. Pandithevan P, Saravana Kumar G. Personalised bone tissue engineering scaffold with controlled architecture using fractal tool paths in layered manufacturing. Virtual Phys Prototyp. 2009;4(3):165-180. doi:10.1080/17452750903055512.

7. Gao F, Chiu SM, Motan DA, et al. Mesenchymal stem cells and immunomodulation: current status and future prospects. Cell Death Dis. 2016;7:e2062. doi:10.1038/cddis.2015.327.

8. Mandai M, Watanabe A, Kurimoto $Y$, et al. Autologous induced stem-cell-derived retinal cells for macular degeneration. $N$ Engl J Med. 2017;376(11):1038-1046. doi:10.1056/NEJMoa1608368.

9. Li Y, Chopp M, Chen J, et al. Intrastriatal transplantation of bone marrow nonhematopoietic cells improves functional recovery after stroke in adult mice. J Cereb Blood Flow Metab. 2000;20(9):13111319. doi:10.1097/00004647-200009000-00006.

10. Kruyt MC, de Bruijn JD, Yuan H, et al. Optimization of bone tissue engineering in goats: a peroperative seeding method using cryopreserved cells and localized bone formation in calcium phosphate scaffolds. Transplantation. 2004;77(3):359-365. doi:10.1097/01.tp.0000102550.58160.39.

11. Harris DT. Stem cell banking for regenerative and personalized medicine. Biomedicines. 2014;2(1):50-79. doi:10.3390/ biomedicines2010050.

12. Betz VM, Betz OB, Harris MB, Vrahas MS, Evans $\mathrm{CH}$. Bone tissue engineering and repair by gene therapy. Front Biosci. 2008;13:833841. doi:10.2741/2724.

13. Munoz Ruiz M, Regueiro JR. New tools in regenerative medicine: gene therapy. Adv Exp Med Biol. 2012;741:254-275. doi:10.1007/978-1-4614-2098-9_17.

14. LuoJ, Sun MH, KangQ, etal. Genetherapyforboneregeneration. Curr GeneTher.2005;5(2):167-179.doi:10.2174/1566523053544218.

15. McMahon JM, Conroy S, Lyons $M$, et al. Gene transfer into rat mesenchymal stem cells: a comparative study of viral and nonviral vectors. Stem Cells Dev. 2006;15(1):87-96. doi:10.1089/ scd.2006.15.87.

16. Zhang Y, Ma W, Zhan Y, et al. Nucleic acids and analogs for bone regeneration. Bone Res. 2018;6(1):37. doi:10.1038/s41413-0180042-7.

17. Wozney JM. The bone morphogenetic protein family and osteogenesis. Mol Reprod Dev. 1992;32(2):160-167. doi:10.1002/ mrd.1080320212.

18. Arvidson $\mathrm{K}$, Abdallah BM, Applegate LA, et al. Bone regeneration and stem cells. J Cell Mol Med. 2011;15(4):718-746. doi:10.1111/ j.1582-4934.2010.01224.x.

19. Augello A, De Bari C. The regulation of differentiation in mesenchymal stem cells. Hum Gene Ther. 2010;21(10):12261238. doi:10.1089/hum.2010.173.

20. Fernandes G, Yang S. Application of platelet-rich plasma with stem cells in bone and periodontal tissue engineering. Bone Res. 2016;4:16036. doi:10.1038/boneres.2016.36.

21. Kouzarides T. Chromatin modifications and their function. Cell. 2007;128(4):693-705. doi:10.1016/j.cell.2007.02.005.

22. Im GI, Shin KJ. Epigenetic approaches to regeneration of bone and cartilage from stem cells. Expert Opin Biol Ther. 2015;15(2):181193. doi:10.1517/14712598.2015.960838.

23. Studer D, Millan C, Ozturk E, Maniura-Weber K, Zenobi-Wong M. Molecular and biophysical mechanisms regulating hypertrophic differentiation in chondrocytes and mesenchymal stem cells. Eur Cell Mater. 2012;24:118-135; discussion 135.

24. Zigdon-Giladi H, Rudich U, Michaeli Geller G, Evron A. Recent advances in bone regeneration using adult stem cells. World J 
Stem Cells. 2015;7(3):630-640. doi:10.4252/wjsc.v7.i3.630.

25. Ferretti C, Mattioli-Belmonte M. Periosteum derived stem cells for regenerative medicine proposals: Boosting current knowledge. World J Stem Cells. 2014;6(3):266-277. doi:10.4252/wjsc. v6.i3.266.

26. Ghasemi S, Mozdarani H, Soleimani M. The Effect of miR-372 on genome instability in MKN-45 cell line. J Isfahan Med Sch. 2015;32(311):2035-2047.

27. Chen CZ, Li L, Lodish HF, Bartel DP. MicroRNAs modulate hematopoietic lineage differentiation. Science. 2004;303(5654):8386. doi:10.1126/science.1091903.

28. Alaiti MA, Ishikawa $M$, Masuda $H$, et al. Up-regulation of miR-210 by vascular endothelial growth factor in ex vivo expanded CD34+ cells enhances cell-mediated angiogenesis. J Cell Mol Med. 2012;16(10):2413-2421. doi:10.1111/j.15824934.2012.01557.x.

29. Hu R, Li H, Liu W, Yang L, Tan YF, Luo XH. Targeting miRNAs in osteoblast differentiation and bone formation. Expert Opin Ther Targets. 2010;14(10):1109-1120. doi:10.1517/14728222.2010.5 12916.

30. Lian JB, Stein GS, van Wijnen AJ, et al. MicroRNA control of bone formation and homeostasis. Nat Rev Endocrinol. 2012;8(4):212227. doi:10.1038/nrendo.2011.234.

31. Beavers KR, Nelson CE, Duvall CL. MiRNA inhibition in tissue engineering and regenerative medicine. Adv Drug Deliv Rev. 2015;88:123-137. doi:10.1016/j.addr.2014.12.006.

32. Dong S, Yang B, Guo H, Kang F. MicroRNAs regulate osteogenesis and chondrogenesis. Biochem Biophys Res Commun. 2012;418(4):587-591. doi:10.1016/j.bbrc.2012.01.075.

33. Li Y, Fan L, Liu S, et al. The promotion of bone regeneration through positive regulation of angiogenic-osteogenic coupling using microRNA-26a. Biomaterials. 2013;34(21):5048-5058. doi:10.1016/j.biomaterials.2013.03.052

34. Glisovic T, Bachorik JL, Yong J, Dreyfuss G. RNA-binding proteins and post-transcriptional gene regulation. FEBS Lett. 2008;582(14):1977-1986. doi:10.1016/j.febslet.2008.03.004.

35. Taft RJ, Pang KC, Mercer TR, Dinger M, Mattick JS. Non-coding RNAs: regulators of disease. J Pathol. 2010;220(2):126-139. doi:10.1002/path.2638.

36. Esteller M. Non-coding RNAs in human disease. Nat Rev Genet. 2011;12(12):861-874. doi:10.1038/nrg3074.

37. Weiler J, Hunziker J, Hall J. Anti-miRNA oligonucleotides (AMOs): ammunition to target miRNAs implicated in human disease? Gene Ther. 2006;13(6):496-502. doi:10.1038/sj.gt.3302654.

38. Chery J. RNA therapeutics: RNAi and antisense mechanisms and clinical applications. Postdoc J. 2016;4(7):35-50.

39. Song KM, Lee $S$, Ban C. Aptamers and their biological applications. Sensors(Basel).2012;12(1):612-631.doi:10.3390/s120100612.

40. Bevilacqua A, Ceriani MC, Capaccioli S, Nicolin A. Posttranscriptional regulation of gene expression by degradation of messenger RNAs. J Cell Physiol. 2003;195(3):356-372. doi:10.1002/jcp.10272.

41. Davidson BL, McCray PB Jr. Current prospects for RNA interference-based therapies. Nat Rev Genet. 2011;12(5):329-340. doi:10.1038/nrg2968.

42. Bleiziffer O, Eriksson E, Yao F, Horch RE, Kneser U. Gene transfer strategies in tissue engineering. J Cell Mol Med. 2007;11(2):206223. doi:10.1111/j.1582-4934.2007.00027.x.

43. Hannon GJ, Rossi JJ. Unlocking the potential of the human genome with RNA interference. Nature. 2004;431(7006):371378. doi:10.1038/nature02870.

44. Gaj T, Gersbach CA, Barbas CF, 3rd. ZFN, TALEN, and CRISPR/ Cas-based methods for genome engineering. Trends Biotechnol.
2013;31(7):397-405. doi:10.1016/j.tibtech.2013.04.004.

45. Doudna JA, Charpentier E. Genome editing. The new frontier of genome engineering with CRISPR-Cas9. Science. 2014;346(6213):1258096. doi:10.1126/science.1258096.

46. Barrangou R, Doudna JA. Applications of CRISPR technologies in research and beyond. Nat Biotechnol. 2016;34(9):933-941. doi:10.1038/nbt.3659.

47. Hsu PD, Lander ES, Zhang F. Development and applications of CRISPR-Cas9 for genome engineering. Cell. 2014;157(6):12621278. doi:10.1016/j.cell.2014.05.010.

48. Bonadio J, Smiley E, Patil P, Goldstein S. Localized, direct plasmid gene delivery in vivo: prolonged therapy results in reproducible tissue regeneration. Nat Med. 1999;5(7):753-759. doi:10.1038/10473.

49. Naldini L. Gene therapy returns to centre stage. Nature. 2015;526(7573):351-360. doi:10.1038/nature15818.

50. Nayerossadat N, Maedeh T, Ali PA. Viral and nonviral delivery systems for gene delivery. Adv Biomed Res. 2012;1:27. doi:10.4103/2277-9175.98152.

51. Gresch O, Engel FB, Nesic D, et al. New non-viral method for gene transfer into primary cells. Methods. 2004;33(2):151-163. doi:10.1016/j.ymeth.2003.11.009.

52. Mason C, Dunnill P. A brief definition of regenerative medicine. Regen Med. 2008;3(1):1-5. doi:10.2217/17460751.3.1.1.

53. Bader AG, Brown D, Winkler M. The promise of microRNA replacement therapy. Cancer Res. 2010;70(18):7027-7030. doi:10.1158/0008-5472.can-10-2010.

54. Nguyen A, Pham D, Nguyen V, et al. A Brief Review of Viral Delivery Systems for Bone Tissue Engineering. Int J Orthop. 2014;1(4):130-139. doi:10.6051/j.issn.2311-5106.2014.01.39.

55. Sheyn D, Mizrahi O, Benjamin S, Gazit Z, Pelled G, Gazit D. Genetically modified cells in regenerative medicine and tissue engineering. Adv Drug Deliv Rev. 2010;62(7-8):683-698. doi:10.1016/j.addr.2010.01.002.

56. Dang JM, Leong KW. Natural polymers for gene delivery and tissue engineering. Adv Drug Deliv Rev. 2006;58(4):487-499. doi:10.1016/j.addr.2006.03.001.

57. Santos JL, Pandita D, Rodrigues J, Pego AP, Granja PL, Tomas $\mathrm{H}$. Non-viral gene delivery to mesenchymal stem cells: methods, strategies and application in bone tissue engineering and regeneration. Curr Gene Ther. 2011;11(1):46-57. doi:10.2174/156652311794520102.

58. Ow Sullivan MM, Green JJ, Przybycien TM. Development of a novel gene delivery scaffold utilizing colloidal gold-polyethylenimine conjugates for DNA condensation. Gene Ther. 2003;10(22):18821890. doi:10.1038/sj.gt.3302083.

59. Sriram M, Sainitya R, Kalyanaraman V, Dhivya S, Selvamurugan $\mathrm{N}$. Biomaterials mediated microRNA delivery for bone tissue engineering. Int J Biol Macromol. 2015;74:404-412. doi:10.1016/j. ijbiomac.2014.12.034.

60. Gower RM, Shea LD. Biomaterial scaffolds for controlled, localized gene delivery of regenerative factors. Adv Wound Care (New Rochelle). 2013;2(3):100-106. doi:10.1089/wound.2011.0325.

61. Hadjizadeh A, Ghasemkhah F, Ghasemzaie N. Polymeric scaffold based gene delivery strategies to improve angiogenesis in tissue engineering: a review. Polym Rev. 2017;57(3):505-556. doi:10.10 80/15583724.2017.1292402.

62. Li H, Ji Q, Chen X, et al. Accelerated bony defect healing based on chitosan thermosensitive hydrogel scaffolds embedded with chitosan nanoparticles for the delivery of BMP2 plasmid DNA. J Biomed Mater Res A. 2017;105(1):265-273. doi:10.1002/ jbm.a.35900 